\title{
Metabolic Syndrome in Indigenous Amerindian Women in Suriname; Less on Waist and More on Weight?
}

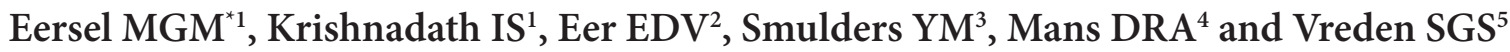 \\ ${ }^{1}$ Department of Public Health, Faculty of Medical Sciences, Anton de Kom University of Suriname, Paramaribo, \\ Suriname, USA \\ ${ }^{2}$ Medische Zending Primary Health Care Suriname, Paramaribo, Suriname, USA \\ ${ }^{3}$ VU University Medical Center, Amsterdam, The Netherlands, Europe \\ ${ }^{4}$ Department of Pharmacology, Faculty of Medical Sciences, Anton de Kom University of Suriname, Paramaribo, \\ Suriname, USA \\ ${ }^{5}$ Department of Internal Medicine and Infectious Diseases, Academic Hospital Paramaribo, Paramaribo, Suriname, \\ USA
}

*Corresponding author: Eersel MGM, Department of Public Health, Faculty of Medical Sciences, Anton de Kom University of Suriname, Medisch Wetenschappelijk Instituut Kernkampweg 5, Paramaribo, Suriname, Tel/Fax: + 597 441071, E-mail: martheersel@gmail.com

Citation: Eersel MGM, Krishnadath IS, Eer EDV, Smulders YM, Mans DRA, et al. (2017) Metabolic Syndrome in Indigenous Amerindian Women in Suriname; Less on Waist and More on Weight? J Obes Overweig 3(2): 201. doi: $10.15744 / 2455-7633.3 .201$

Received Date: June 02, 2017 Accepted Date: November 27, 2017 Published Date: November 29, 2017

\begin{abstract}
Background: The indigenous Amerindian populations living in the southern interior part of Suriname have to date largely maintained their traditional hunter-gatherer life-style. In this study we compared the prevalence of metabolic syndrome (MeTS) and its component risk factors between indigenous Amerindian women of the interior of Suriname, with indigenous Amerindian women living in the coastal-rural areas who have a more urbanized lifestyle. We focused on women since the Suriname Health study showed that Indigenous women had the second highest MeTS prevalence nationwide.
\end{abstract}

Methods: A subset of secondary data from the Suriname Health Study was used. The prevalence of cardiovascular risk factors and of MeTS and its component risk factors were compared between the two populations, using analyses of variance and chi-square tests.

Results: Both groups had comparable MeTS prevalence's of almost 40\%. Elevated fasting blood glucose occurred twice more frequently in the coastal-rural compared to the interior women (51.2\% vs. $24.7 \%)$. The prevalence of pre-diabetes was statistically significantly higher in the coastal-rural compared to the interior $(43.1 \%$ vs. $17.3 \%)$, while diabetes mellitus and hypertension rates did not differ statistically significantly between the two groups (resp. $19.1 \%$ vs. $14.1 \%$ and $5.8 \%$ vs. $4.1 \%$ ). Elevated triglycerides were more than twice more prevalent in the interior compared to the coastal-rural area ( $43.1 \%$ vs. $17.3 \%)$, possibly related to alcohol consumption. The obesity prevalence was around $50 \%$ in the coastal-rural women, almost three times higher than in the interior, while both groups had comparable prevalence's of an increased waist circumference and waist/height ratio (around 80\%). Lifestyle differed statistically significantly between the coastal-rural and interior women: coastal-rural women smoked more, had less vigorous daily activities, more frequently consumed meals from restaurants or fast food and more frequently used sugary soft drinks.

Conclusion: Despite a comparable MeTS prevalence of almost 40\%, behavioral and other CVD risk factors differed statistically significantly between women living in coastal-rural areas and those in the interior. Interior women had statistically significantly lower pre-diabetes and obesity rates. In both groups the majority of the women (around 80\%) had an increased waist circumference, which could be common in Amerindian people, unrelated to cardiovascular risk and needs to be studied further.

Keywords: Indigenous; Amerindian; Suriname; Medical Mission; MeTS; Obesity; Waist cirumference; Hypertriglyceridemia; Lifestyle List of Abbreviations: BMI: Body mass index; CVD: Cardiovascular disease; EFG: Elevated fasting glucose; HDL: High density lipoprotein; MeTS: Metabolic syndrome; WC: Waist circumference; WHO: World Health Organization

\section{Background}

Epidemiological studies have revealed a high prevalence of obesity, type-2 diabetes and coronary heart disease in Indigenous populations who have undergone a rapid transition from a primitive to an urban life-style [1-3]. Throughout the world, such rapid changes mainly in diet and habitual lifestyle may thus lead to increases in the prevalence of cardiovascular disease (CVD) 
and diabetes mellitus [4]. Indigenous people in Latin America and the Caribbean also face these challenges. Rising problems of obesity, diabetes mellitus and hypertension have been recorded especially in reserves where Indigenous people have been forced to abandon their original physically intensive lifestyle and their diet $[1,5]$. On the other hand there are still Indigenous people which live in isolated communities maintaining more or less their traditional life style and experiencing a low disease burden of CVD $[1,6]$.

The metabolic syndrome (MeTS) has been defined as a cluster of interconnected CVD risk factors which increase the risk of CVD and type-2 diabetes mellitus [7]. The prevalence of MeTS is increasing rapidly worldwide especially in developing countries and reflects a transition from a traditional to a Western-like lifestyle [8].

There are few data on MeTS in Indigenous populations in Latin America. A recent study has highlighted the alarming increase of weight excess and of the burden of non-communicable diseases, suggesting the prevalence of MeTS could be elevated among these Indigenous populations [9].

The current study focuses on Amerindian people of the Republic of Suriname. This country is located on the north-east coast of South America and is part of the Amazon River Basin. Its remote south and south-western interior part are inhabited by Indigenous populations belonging predominantly to the Trio people (Figure 1).

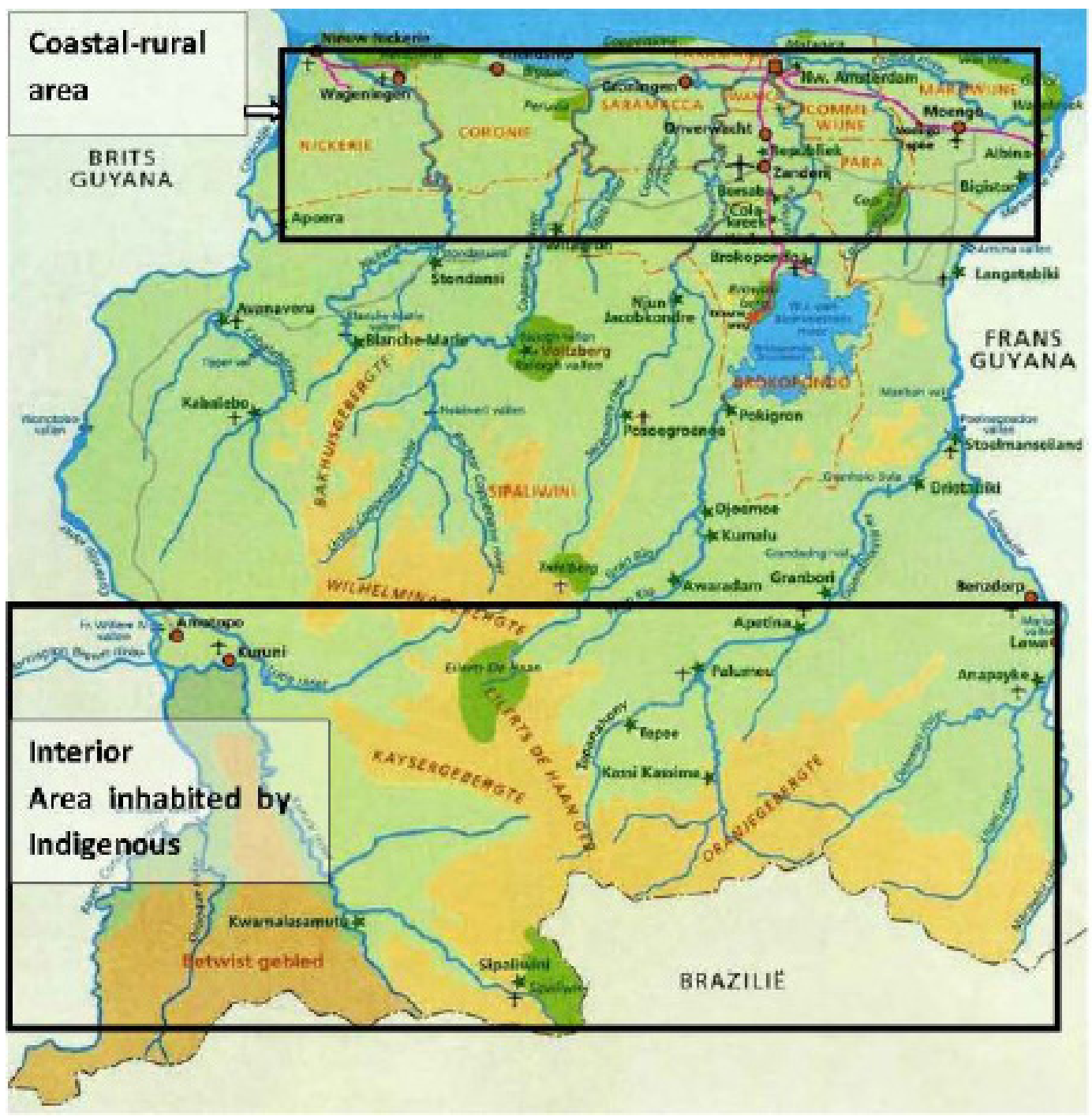

Figure 1: Map of Suriname

Their population size is about 2,500 [10]. They have largely maintained their traditional life-style of hunting, fishing, and crop cultivation. The Indigenous in the coastal-rural areas of Suriname belong predominantly to the Carib people who have been living in coastal-rural villages for decades in closer contact with urban areas through work, purchase of goods etc. Their population size is approximately 9000 (1.6\% of the total population) [11].

In this study we compared the prevalence of MeTS and its component risk factors between Indigenous Trio women of the interior southern part of Suriname, with Indigenous women living in the coastal-rural areas of the country. We focused on women since the Suriname Health study showed that Indigenous women had the second highest MeTS prevalence nationwide [12]. 


\section{Methods}

The aim of this study was to assess whether there are differences in the magnitude of behavioural risk factors, MeTS and its component risk factors between Amazonian Indigenous hunter gatherer women living in the southern part (interior) of Suriname and Indigenous women living in the coastal-rural areas of the country.

For our analysis we used a subset of data collected from Indigenous female participants living in the coastal- rural areas and in the interior (south) of the country. We used secondary data from the Suriname Health Study, a cross-sectional national surveillance survey among people 15-64 years, on non-communicable disease risk factors carried out from March-September 2013 [13]. In this study a multistage cluster, household population cross-sectional design was used to select respondents aged 15 to 64 years, men and non-pregnant women, of the 6 main ethnic groups including the Indigenous [13].

The Indigenous participants from the interior of the country had been randomly selected from the largest Trio village Kwamalasamutu, located near the southern border with Brazil [13]. This Trio village was selected because of its representativeness and the relatively high population density, namely $20 \%$ of all interior indigenous Amerindians. The number of study participants from this village was oversampled to compensate for high travel costs to the other smaller settlements scattered over the interior [13]. The Indigenous participants from the coastal-rural districts of the country were randomly selected from coastal-rural clusters. This group was oversampled as well to compensate for the relatively small percentage of indigenous Amerindians in the Surinamese population [13].

\section{Data collection}

Data were collected using the validated WHO STEPS to chronic disease risk factor surveillance tool, which uses three levels of data collection: Step1 (a validated questionnaire) included the recording of information on demographics and non-communicable disease (NCD) risk factors (smoking, physical activity, dietary habits such as consumption of fast food and restaurant food and sugary soft drinks); Step 2 (Physical measurements) included body weight and height, waist circumference (WC) and systolic and diastolic blood pressure measurements; Step 3 (Blood samples) included the collection of fasting (at least 12 hours overnight) blood samples for laboratory analysis on the blood glucose, cholesterol and triglyceride levels [13].

\section{Data analysis}

Body mass index (BMI) was based on measurements of weight and height and expressed as body weight in kilograms divided by the square of the height in meters. BMI categories were defined according to guidelines by the World Health Organization (WHO): underweight-standard weight $\mathrm{BMI}<25.0$, Overweight BMI 25.0-29.9 and Obesity BMI $\geq 30$ [14]. The cut point of $80 \mathrm{~cm}$ (for women) for the WC was used to determine abdominal obesity [15]. The recommended cut point of 0.5 was used for the waist/ height ratio [16].

Hypertension was classified as systolic blood pressure $\geq 140$ and/or a diastolic blood pressure $\geq 90$ and/or self reporting of being on anti-hypertension medication [17]. Diabetes mellitus was classified as a fasting blood glucose $\geq 7.0 \mathrm{mMol} / \mathrm{L}$ and/or self-reporting use of anti-diabetic medication. An 8 hours fasting blood glucose between 6.1-6.9 mMol/L was classified as pre-diabetes [18]. The cut points $1.29 \mathrm{mMol} / \mathrm{L}$ and $2.8 \mathrm{mMol} / \mathrm{L}$ were used to determine HDL-C dyslipidemia and hypertriglyceridemia respectively [19].

The definition of MeTS used in this article adheres to the IDF/AHA/NHLBI consensus [7], which is based on three or more of the following components: blood pressure $>=130 / 85$ or using anti-hypertensive medication; WC $>=80 \mathrm{~cm}$ (for women); fasting glucose $>=5.6 \mathrm{mMol} / \mathrm{L}$ and/or using anti-diabetic medication; HDL-C cholesterol $<1.29 \mathrm{mMol} / \mathrm{L}$ or using lipid lowering medication; Triglycerides $>=1.7 \mathrm{mMol} / \mathrm{L}$ or using lipid lowering medication.

\section{Statistical analysis}

The prevalences of behavioural risk factors (Step 1 measurements) between the two sub-populations were compared using the Chi square test. Continuous variables (Step 2 and Step 3 measurements) were expressed as means and standard deviations or, for the variables not normally distributed, the median and interquartile range were used. Analysis of variance (Student $t$ test) and non-parametric tests were used to compare means between the two populations. Discrete variables were expressed as proportions with 95\% confidence intervals. The prevalence of cardiovascular risk factors and of MeTS and its component risk factors were compared between the two populations using the Chi square test. All analyses were performed using the software Statistical Package for Social Sciences (SPSS) version 22. The statistical significance level was fixed at $\mathrm{p}<0.05$.

\section{Ethical approval}

The Suriname Health Study was approved by the Ethics Committee of the Ministry of Health of Suriname and written consent was obtained from the study participants [13].

\section{Results}

Figure 2 provides an overview of the number of included women by age group for the coastal-rural and interior regions in respectively Step 1 (socio-demographic and behavioral risk factor questionnaire), Step 2 (body measurements: waist, weight, height, systolic and diastolic blood pressure) and Step 3 (laboratory measurements: fasting blood glucose and blood lipids). 


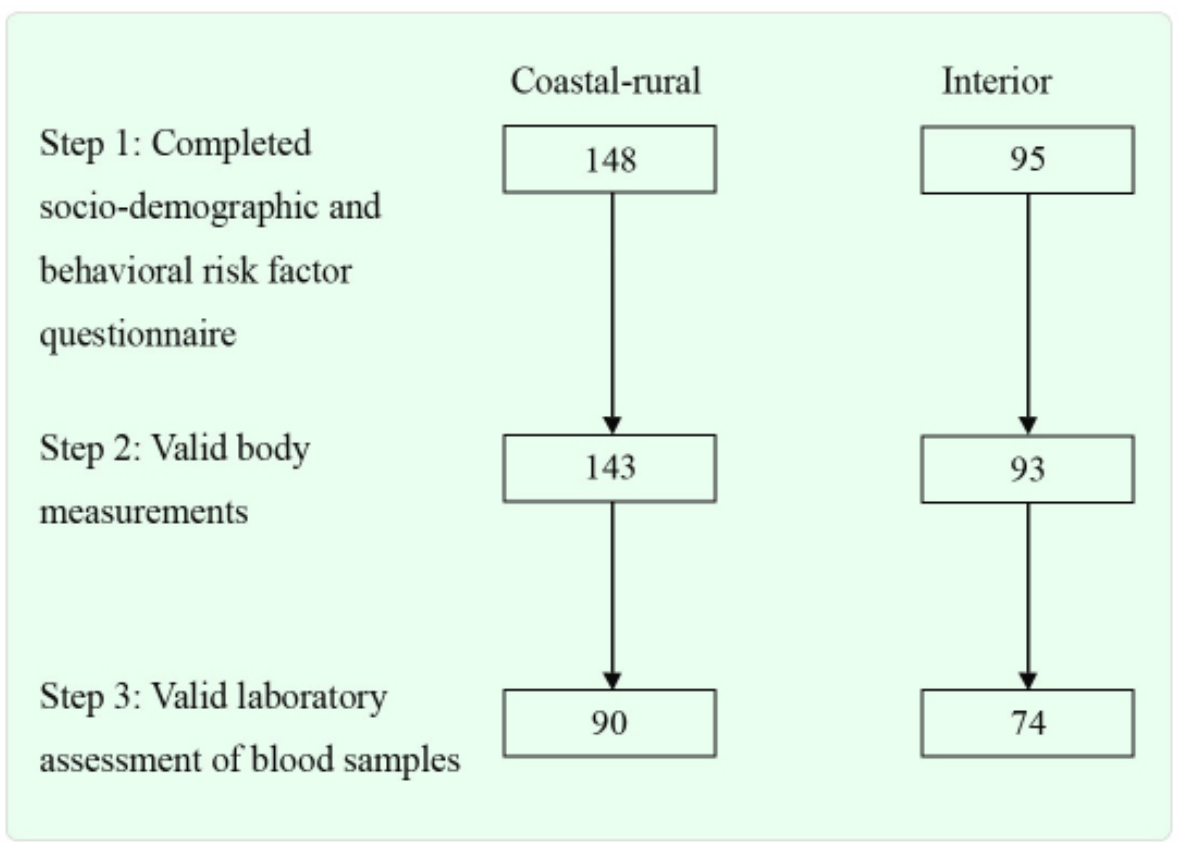

Figure 2: Number of Indigenous women included in the 1-3 Step analysis by region

Table 1 illustrates the subject's characteristics for the interior and coastal-rural areas.

\begin{tabular}{|c|c|c|c|}
\hline Characteristics & Interior & Coastal-rural & $\mathbf{p}$ \\
\hline Step 1 & $\mathrm{n}=95$ & $\mathrm{n}=148$ & \\
\hline Age, mean (SD) & $34.3(13.7)$ & $36.5(13.4)$ & 0.2 \\
\hline Smoking, \% (95\% CI) & 0 & $5.4(0-16.2)$ & $0.04^{*}$ \\
\hline $\begin{array}{c}\text { Intensive physical activity }>=5 \text { days per } \\
\text { week, } \%(95 \% \mathrm{CI})\end{array}$ & $40(30.4-49.6)$ & $2.7(0-5.5)$ & $0.0001^{*}$ \\
\hline $\begin{array}{l}\text { Rarely/never consume restaurant or fast } \\
\text { food, } \%(95 \% \mathrm{CI})\end{array}$ & 100 & $82.8(73.6-92.0)$ & $0.0001^{*}$ \\
\hline $\begin{array}{l}\text { Rarely/never consume sugary soft drinks, } \\
\qquad \%(95 \% \mathrm{CI})\end{array}$ & $66(56.8-75.2)$ & $21(11.2-30.8)$ & $0.0001^{*}$ \\
\hline Step 2 & $\mathrm{n}=93$ & $n=143$ & \\
\hline Weight, mean (SD) kg & $58.2(10.6)$ & $68.0(13.0)$ & $0.0001^{* *}$ \\
\hline Height, mean (SD) cm & $149.6(4.7)$ & $152.2(5.7)$ & $0.0001^{* *}$ \\
\hline $\mathrm{WC}$, mean $(\mathrm{SD}) \mathrm{cm}$ & $89.5(10.7)$ & $90.5(11.6)$ & 0.34 \\
\hline $\mathrm{SBP}$, mean $(\mathrm{SD}) \mathrm{mmHg}$ & $111.1(15.0)$ & $114.1(19.1)$ & 0.2 \\
\hline DBP, mean (SD) mmHg & $73.8(9.0)$ & $76.4(11.1)$ & 0.09 \\
\hline Step 3 & $\mathrm{n}=74$ & $\mathrm{n}=90$ & \\
\hline $\begin{array}{l}\text { Fasting glucose }{ }^{*} \text {, median (95\% range) } \\
\mathrm{mMol} / \mathrm{L}\end{array}$ & $5.1(4.4-6.9)$ & $5.6(4.7-11.1)$ & $0.006^{\star *}$ \\
\hline $\begin{array}{l}\text { Triglyceride *, median (95\% range) } \\
\text { mMol/L }\end{array}$ & $1.5(0.5-3.5)$ & $1.1(0.5-2.5)$ & $0.007^{* *}$ \\
\hline HDL-C, mean (SD) mMol/L & $1.2(0.3)$ & $1.2(0.3)$ & 0.6 \\
\hline
\end{tabular}

*skewness $>2.0$; Mann-Whitney non parametric test performed

$* *$ significant difference at 0.05 confidence level

Table 1: Participants characteristics. Comparison between Indigenous women living in the interior and coastal-rural areas, Suriname Health Study 2013

Indigenous women from the interior had a statistically significantly more favorable behavioral risk profile with regards to smoking, physical activity and diet, when compared to coastal-rural Indigenous. The differences in mean height and weight (resp. $2 \mathrm{~cm}$ and $10.8 \mathrm{~kg}$ ) between the two populations were statistically significant (Table 1). However, the WCs were similar. The systolic and diastolic blood pressures did not differ significantly, while the fasting blood glucose was statistically significantly higher in the coastal rural women. On the other hand triglyceride levels were statistically significantly higher in the interior group.

Obesity was almost 3 times more prevalent in the coastal-rural women while increased WC $(>80 \mathrm{~cm})$ and/or waist/height ratio $(>0.5)$ did not differ significantly (Table 2$)$. Hypertension and diabetes mellitus prevalence did not differ significantly, but prediabetes occurred more frequently in the coastal-rural women (Table 2). 


\begin{tabular}{|c|c|c|c|}
\hline CVD risk factor & Interior & Coastal-rural & $\mathbf{p}$ \\
\hline $\mathrm{BMI}>=30, \%(95 \% \mathrm{CI})$ & $16.3(9.2-23.4)$ & $48.6(36.6-60.6)$ & $0.0001^{*}$ \\
\hline $\mathrm{WC}>80 \mathrm{~cm}, \%(95 \% \mathrm{CI})$ & $81.5(74.0-89.0)$ & $82.6(73.5-91.7)$ & 0.8 \\
\hline Waist/Height ratio $>0.5, \%(95 \% \mathrm{CI})$ & $94.5(90.1-98.9)$ & $86.8(78.7-94.9)$ & 0.06 \\
\hline $\begin{array}{c}\text { Hypertension }(\mathrm{SBP} \geq 140 \text { and/or } \mathrm{DBP} \geq 90 \\
\text { or self reported hypertension medication } \\
\text { use), } \%(95 \% \mathrm{CI})\end{array}$ & $14.1(7.4-20.8)$ & $19.1(9.7-28.5)$ & 0.3 \\
\hline $\begin{array}{l}\text { Diabetes mellitus (fasting blood glucose } \\
\geq 7.0 \text { or self reported diabetes medication } \\
\text { use), } \% \text { ( } 95 \% \mathrm{CI})\end{array}$ & $4.1(0.7-7.5)$ & $5.8(1.4-10.2)$ & 0.6 \\
\hline $\begin{array}{l}\text { Pre-diabetes (fasting blood glucose } 6.1 \text { - } \\
6.9), \%(95 \% \mathrm{CI})\end{array}$ & $5.1(1.3-8.9)$ & $21.2(13.4-29.0)$ & $0.01^{*}$ \\
\hline
\end{tabular}

${ }^{*} \mathrm{p}$ significant at the 0.05 confidence level

Table 2: Comparison of the prevalence of obesity, central obesity, hypertension, diabetes mellitus and pre-diabetes,

between Indigenous women living in the interior and coastal-rural areas, Suriname Health Study 2013

We found that a statistically significantly higher percentage of women from the interior than from the coastal-rural area had an increased WC and were not obese (resp. 65\% vs. 34\%) (Figure 3).

\section{coastal-rural}

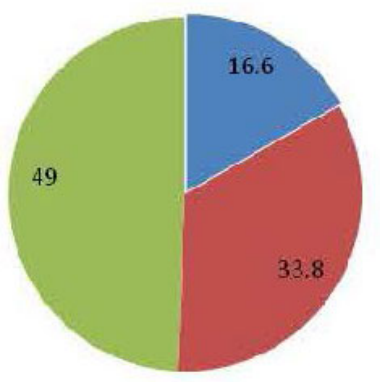

interior

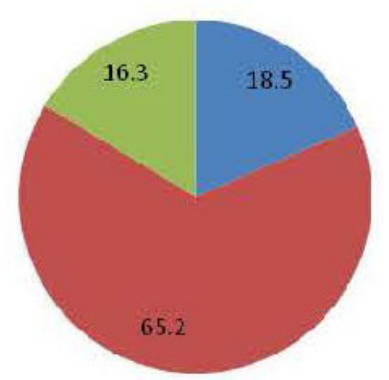

BMl $<30$, Waist $<80 \mathrm{~cm}$

BMl $<30$, Waist $>=80 \mathrm{~cm}$

BMl $>=30$, Waist $>=80 \mathrm{~cm}$

\section{Chi square $=4.0 ; p=0.044$}

Figure 3: Comparison of body composition between Indigenous women living in the interior and the coastal-rural areas, Suriname Health Study 2013

The prevalence of MeTS did not differ significantly between the two groups (Table 3). Both populations had a high prevalence (above $80 \%$ ) of an increased WC and low HDL-C levels (around 50\%). Elevated triglyceride levels were more prevalent in the interior group while elevated fasting glucose (EFG) levels were more prevalent in the coastal-rural women.

\begin{tabular}{|c|c|c|c|}
\hline MeTS and component risk factors & Interior & Coastal-rural & $\mathbf{p}$ \\
\hline & $\mathrm{n}=74$ & $\mathrm{n}=90$ & \\
\hline MeTS ( $\geq 3$ risk factors), $\%$ (95\%CI) & $35.6(28.9-43.8)$ & $38.1(28.9-47.3)$ & 0.7 \\
\hline $\mathrm{WC}>80 \mathrm{~cm}), \%(95 \% \mathrm{CI})$ & $81.5(74.8-88.2)$ & $82.6(75.4-89.8)$ & 0.8 \\
\hline Elevated triglyceride $\geq 1.7), \%(95 \% \mathrm{CI})$ & $43.1(34.6-51.6)$ & $17.3(10.1-24.5)$ & $0.0001^{*}$ \\
\hline HDL-C<1.29), \% (95\%CI) & $48.3(39.7-56.9)$ & $51.7(42.2-60.7)$ & 0.6 \\
\hline $\begin{array}{l}\text { Elevated fasting glucose }(\geq 5.6) \text { or self reported diabetes } \\
\text { medication use), } \%(95 \% \mathrm{CI})\end{array}$ & $24.7(17.3-32.1)$ & $51.2(41.7-60.7)$ & $0.0001^{*}$ \\
\hline $\begin{array}{l}\text { Elevated blood pressure (SBP } \geq 130 \text { and/or } \mathrm{DBP} \geq 85 \text { or } \\
\text { self reported hypertension medication use), } \%(95 \% \mathrm{CI})\end{array}$ & $20.5(13.6-27.4)$ & $25.0(16.8-33.2)$ & 0.5 \\
\hline
\end{tabular}

* $\mathrm{p}$ significant at the 0.05 confidence level

Table 3: Comparison of MeTS and its component risk factors between Indigenous women living in the interior and coastal-rural areas, Suriname Health Study 2013 


\section{Discussion}

Our study found that almost 40\% in both Indigenous women living in the interior and those in the coastal-rural areas had MeTS. Comparing the risk factor components of MeTS between the two groups, we found that EFG was more than twice more prevalent in the coastal-rural women The prevalence of pre-diabetes was statistically significantly higher in the coastal-rural women, while the prevalence of diabetes mellitus and hypertension did not differ significantly between the two groups. Elevated triglycerides were more common in women from the interior. We also found an obesity prevalence of around 50\% in the coastal- rural women, almost three times higher than in the interior, while both groups had comparable high prevalence's of an increased WC and waist/ height ratio. Lifestyle between the coastal-rural and interior women differed statistically significantly: the coastal-rural women smoked more, had less vigorous daily activities, consumed more frequently meals from restaurants or fast food and drank more frequently sugary soft drinks. Acculturation of lifestyle is already increasing among the indigenous in the interior, especially among the Wayana, where an increase in consumption of canned and processed foods has been documented [20,21]. The prevalence of MeTS in both our study subgroups was comparable to the national average for women (42.3\%) [12]. Both diabetes mellitus and hypertension were less prevalent than the national average for women (resp. 13\% and 20\%) [22-23]. The relatively high prevalence of Me TS found in both study groups coupled with the relatively low prevalence of hypertension and diabetes mellitus could be an indication that both these subpopulations are in epidemiological transition [2,24], though at different stages. The Indigenous women in the interior in particular, had statistically significantly lower EFG levels and lower pre-diabetes and obesity rates than the coastal-rural women which could be attributed to their traditional horticulturalist lifestyle which includes harsh daily labor. The hypertriglyceridemia in this group, could be attributed to the heavy consumption of kasiri, a locally brewed beer derived from cassava $[20,25,26]$. The high prevalences of both obesity and EFG levels in the coastal-rural group coupled with less vigorous daily activity and westernization of food consumption puts this group at a greater risk for developing CVD. The value of the WC in both study groups in predicting CVD risk is debatable. Most studies of Indigenous people in South America reveal a relatively high prevalence of low HDL-C and increased WC for women [24,27-29]. High obesity (BMI>30) prevalences were particularly more frequently observed in Indigenous populations with an acculturated sedentary life style [9,30,31]. A study among the Xavante living in a reservation in Brazil revealed a high prevalence of MeTS of 66\% [9]. Eighty one percent of that study population was obese and almost $30 \%$ had diabetes mellitus, which places them on the same level of CVD risk as Indigenous populations living in reservations in the USA, Canada and elsewhere [32-34]. On the other hand a recently published study among a traditionally living horticultural indigenous population in Bolivia revealed a very low prevalence of CVD risk factors until old age [6]. No previous CVD risk factor studies have been documented in the indigenous Amerindians living in the interior part of Suriname; except for an anthropometric study carried out between 1968-1970 [35]. The average BMI of the women of Kwamalasamutu in that study was 22 [35]. The average BMI in our study, conducted 45 years later was 26 . The gradual decline of the burden of infectious diseases during the past 50 years during which the local availability of medical services improved, could have contributed to better health and an increase in body mass [36]. Another study on serum proteins and red cell enzymes carried out in the early 1970s among Trio and Wajana Indians in Suriname revealed that the majority of the study participants had haptoglobin 2-1 and 2-2 [37]. Studies show that these haptoglobine pheno- and genotypes provide a greater susceptibility to diabetes mellitus and cardiovascular disease [38]. This could suggest that these populations have a genetic predisposition, like other Indigenous populations, to develop diabetes mellitus and cardiovascular diseases.

The small sample size and cross-sectional design of our study groups limits the generalizability of our findings and the ability to analyze temporal trends. But importantly, our findings suggest that the high prevalence of MeTS found, might be inflated since it incorporates WC. An increased WC could be common in Indigenous people, unrelated to cardiovascular risk. The combination of a big waist and a relatively short stature resulted in an increased waist/height ratio ( $>0.5)$ of the vast majority of both our study groups. The usefulness of MeTS in predicting CVD as well as the equal weight of the various component risk factors is questionable [39]. Furthermore there is conflicting evidence on the use of either the WC, the BMI, the waist/height ratio or the $\mathrm{BMI}$ as predictors of CVD [40-43]. This needs to be studied further.

\section{Conclusion}

There is a statistically significant difference in behavioral and other CVD risk factors between Indigenous women living in coastalrural areas and those living in the interior, despite our finding that both groups have a comparable MeTS prevalence of almost $40 \%$. An increased WC could be common in indigenous Amerindian people, unrelated to cardiovascular risk. This needs to be studied further. The actual burden of diabetes mellitus and hypertension in women living in the interior as well as coastal-rural areas apparently is not as grave when compared to other Indigenous societies on the continent. But the levels of obesity, prediabetes and EFG in the coastal-rural women may be an indication that for them the clock is ticking in terms of increased CVD risk, especially considering their seemingly acculturated lifestyle. For both groups, especially for the interior women, there still appears to be window of opportunity for the implementation of healthy life style promotion, risk factor screening (including weight instead of waist monitoring?) and early therapeutic interventions to prevent or mitigate a potential surge in CVDs.

\section{Ethics approval and consent to participate}

The Suriname Health Study was approved by the Ethics Committee of the Ministry of Health of Suriname and written consent was obtained from the study participants (VG004-2013). 


\section{Funding}

The Suriname Health Study was funded by the Ministry of Health of Suriname.

\section{Author's contributions}

ME analyzed and interpreted the data and was the major contributor in writing the manuscript, IK coordinated the data collection and assisted with the statistical data analysis, EvE, YS, DM and SV contributed to the interpretation of the results and edited the manuscript. All authors read and approved the final manuscript.

\section{Acknowledgements}

The authors gratefully acknowledge the participants in the Suriname Health Study and thank the coordination and entire field team of the Suriname Health Study for their work in the collection of the data, especially Christel Antonius-Smits Lic., from the department of Public Health, Faculty of Medical Sciences, Anton de Kom University of Suriname, for her participation in the coordination team and her assistance with the data collection and control.

\section{References}

1. Montenegro RA, Stephens C (2006) Indigenous health in Latin America and the Caribbean. Lancet 367: $1859-69$.

2. Broussard BA, Sugarman JR, Bachman-Carter K, Booth K, Stephenson L, et al. (1995) Toward comprehensive obesity prevention programs in Native American communities. Obes Res 3: 289s-297s.

3. Yu CH, Zinman B (2007) Type 2 diabetes and impaired glucose tolerance in aboriginal populations: a global perspective. Diabetes Res Clin Pract 78: 159-70.

4. Knowler WC, Pettitt DJ, Saad MF, Charles MA, Nelson RG, et al. (1991) Obesity in the Pima Indians: its magnitude and relationship with diabetes. Am J Clin Nutr 53: 1543S-51S.

5. Welch JR, Ferreira AA, Santos RV, Gugelmin SA, Werneck G (2009) Nutrition Transition, Socioeconomic Differentiation, and Gender Among Adult Xavante Indians, Brazilian Amazon. Hum Ecol 37: 13-26.

6. Kaplan H, Thompson RC, Trumble BC, Wann LS, Allam AH, et al. (2017) Coronary atherosclerosis in indigenous South American Tsimane: a cross-sectional cohort study. Lancet 389: 1730-1739.

7. International Diabetes Federation (2006) The IDF consensus worldwide definition of the Metabolic Syndrome.

8. Kassi E, Pervanidou P, Kaltsas G, Chrousos G (2011) Metabolic syndrome: definitions and controversies. BMC Med 9: 48.

9. Soares LP, Fabbro ALD, Silva AS, Sartorelli DS, Franco LF, et al. (2015) Prevalence of metabolic syndrome in the Brazilian Xavante indigenous population. Diabetol Metab Syndr 7: 105.

10. Registration data Medical Mission Primary Health Care Suriname 2013, unpublished data.

11. Algemeen Bureau voor de Statistiek (2013) Results Eighth (8th) Volks - and Housing Census in Suriname (Resultaten Achtste (8ste) Volks- en Woningtelling in Suriname) (Volume 1). Edited by Algemeen Bureau voor de Statistiek/ Census kantoor in Suriname. 2001; No. 294/2013-05.

12. Krishnadath ISK, Toelsie JR, Hofman A, Jaddoe VWV (2016) Ethnic disparities in the prevalence of metabolic syndrome and its risk factors in the Suriname Health Study: a cross-sectional population study. BMJ Open 6: e013183.

13. Krishnadath IS, Smits CC, Jaddoe VW, Hofman A, Toelsie JR (2015) A National Surveillance Survey on Noncommunicable Disease Risk Factors: Suriname Health Study Protocol. JMIR Res Protoc 4: e75.

14. World Health Organization (2016) Obesity and overweight, Switzerland.

15. World Health Organization (2008) Waist circumference and waist-hip ratio; Report of a WHO Expert consultation, Switzerland.

16. Ashwell M, Mayhew L, Richardson J, Rickayzen B (2014) Waist-to-height ratio is more predictive of years of life lost than body mass index. PLoS One 9: e103483.

17. World Health Organization (2013) A global brief on hypertension; Silent killer, global public health crisis, Switzerland.

18. World Health Organization (2006) Definition and diagnosis of diabetes and intermediate hyperglycemia; Report of a WHO/IDF consultation, Switzerland.

19. World Health Organization (2007) Prevention of Cardiovascular Disease: Guidelines for assessment and management of cardiovascular risk, Switzerland.

20. Boven K (2006) Survival in a frontier society; Processes of change among the Wayana in Suriname and French Guyana (with a summary in English) [Overleven in een grensgebied : veranderingsprocessen bij de Wayana in Suriname en Frans-Guyana]. Proefschrift ter verkijging van de graad van doctor aan de Universiteit Utrecht. IBS, Rozenberg Publishers.

21. Heemskerk M, Deloye K (2007) Trio baseline study; A sustainable livelihoods perspective on the Trio Indigenous Peoples of South Suriname. The Amazon Conservation team Suriname.

22. Krishnadath ISK, Nahar-van Venrooij LM, Jaddoe VWV, Toelsie JR (2016) Ethnic differences in prediabetes and diabetes in the Suriname Health Study. BMJ Open Diabetes Res Care 4: e000186.

23. Krishnadath ISK, Jaddoe VWV, Nahar-van Venrooij LM, Toelsie JR (2016) Ethnic differences in prevalence and risk factors for hypertension in the Suriname Health Study: a cross sectional population study. Popul Health Metr 14: 33.

24. Santos JL, Pérez-Bravo F, Carrasco E, Calvillán M, Albala C (2001) Low prevalence of type 2 diabetes despite a high average body mass index in the Aymara natives from Chile. Nutrition 17: 305-9.

25. Van der Kuyp E (1970) Voedingsgewoonten in Suriname, Voeding, 31ste jaargang no 8, 15 augustus 1970.

26. Van de Wiel A (2012) The effect of alcohol on postprandial and fasting triglycerides. Int J Vasc Med 2012: 862504.

27. Gimeno SGA, Rodrigues D, Canó EN, Lima EES, Schaper M, et al. (2009) Cardiovascular risk factors among Brazilian Karib indigenous peoples: Upper Xingu, Central Brazil, 2000-3. J Epidemiol Community Health 63: 299-304.

28. Tavares EF, Vieira-Filho JP, Andriolo A, Sañudo A, Gimeno SG, et al. (2003) Metabolic profile and cardiovascular risk patterns of an Indian tribe living in the Amazon Region of Brazil. Hum Biol 75: 31-46. 
29. Dal Fabbro AL, Franco LJ, da Silva AS, Sartorelli DS, Soares LP, et al. (2014) High prevalence of type 2 diabetes mellitus in Xavante Indians from Mato Grosso, Brazil. Ethn Dis 24: 35-40.

30. Orden AB, Oyhenart EE (2006) Prevalence of overweight and obesity among Guaraní-Mbyá from Misiones, Argentina. Amer J Hum Biol 18: 590-9.

31. Lagranja ES, Phojanakong P, Navarro A, Valeggia CR (2015) Indigenous populations in transition: An evaluation of metabolic syndrome and its risk factors among the Toba of northern Argentina. Ann Hum Biol 42: 84-90.

32. Hanley AJ (2006) Diabetes in Indigenous people. Medscape Diabetes \& Endocrinology.

33. Sylvia H. Ley, Stewart B. Harris, Mary Mamakeesick, Tina Noon, Edith Fiddler, et al. (2009) Metabolic syndrome and its components as predictors of incident type 2 diabetes mellitus in an Aboriginal community. CMAJ 180: 617-24.

34. Lucero AA, Lambrick DM, Faulkner JA, Fryer S, Tarrant MA, et al. (2014) Modifiable Cardiovascular Disease Risk Factors among Indigenous Populations. Adv Prev Med 2014: 547018.

35. Glanville EV, Geerdink RA (1970) Skinfold thickness, body measurements and age changes in Trio and Wajana Indians of Surinam. Am J Phys Anthropol 32: 455-61.

36. Eersel M (2017) Fifty Years Of Primary Health Care In The Rainforest. Temporal Trends In Morbidity And Mortality In Indigenous Amerindian Populations Of Suriname.

37. Geerdink RA, Bartstra HA, Schillhorn van Veen JM (1974) Serum proteins and red cell enzymes in Trio and Wajana Indians from Surinam.Am J Hum Genet 26: 581-7.

38. Peretti de Albuquerque Wobeto V, Zaccariotto TR, de Fátima Sonati M (2008) Polymorphism of human haptoglobin and its clinical importance. Genetics and Molecular Biology 31: 602-20.

39. Borch-Johnsen K, Wareham N (2010) The rise and fall of the metabolic syndrome. Diabetologia 53: 597-9.

40. Alvim Rde O, Mourao-Junior CA, de Oliveira CM, Krieger JE1, Mill JG, et al. (2014) Body mass index, waist circumference, body adiposity index, and risk for type 2 diabetes in two populations in Brazil: general and Amerindian. PLoS One 9: e100223.

41. Márcio Weissheimer Lauria, Lívia Maria Pinheiro Moreira, George Luiz Lins Machado-Coelho, Raimundo Marques do Nascimento Neto, Maria Marta Sarquis Soares, et al. (2013) Ability of body mass index to predict abnormal waist circumference: receiving operating characteristics analysis. Diabetol Metab Syndr 5: 74 . 42. Adegbija O, Hoy WE, Wang Z (2015) Corresponding waist circumference and body mass index values based on 10-year absolute type 2 diabetes risk in an Australian Aboriginal community. BMJ Open Diabetes Res Care 3: e000127.

43. Tulloch-Reid MK, Williams DE, Looker HC, Hanson RL, Knowler WC (2003) Do measures of body fat distribution provide information on the risk of type 2 diabetes in addition to measures of general obesity? Comparison of anthropometric predictors of type 2 diabetes in Pima Indians. Diabetes Care 26: 2556-61.

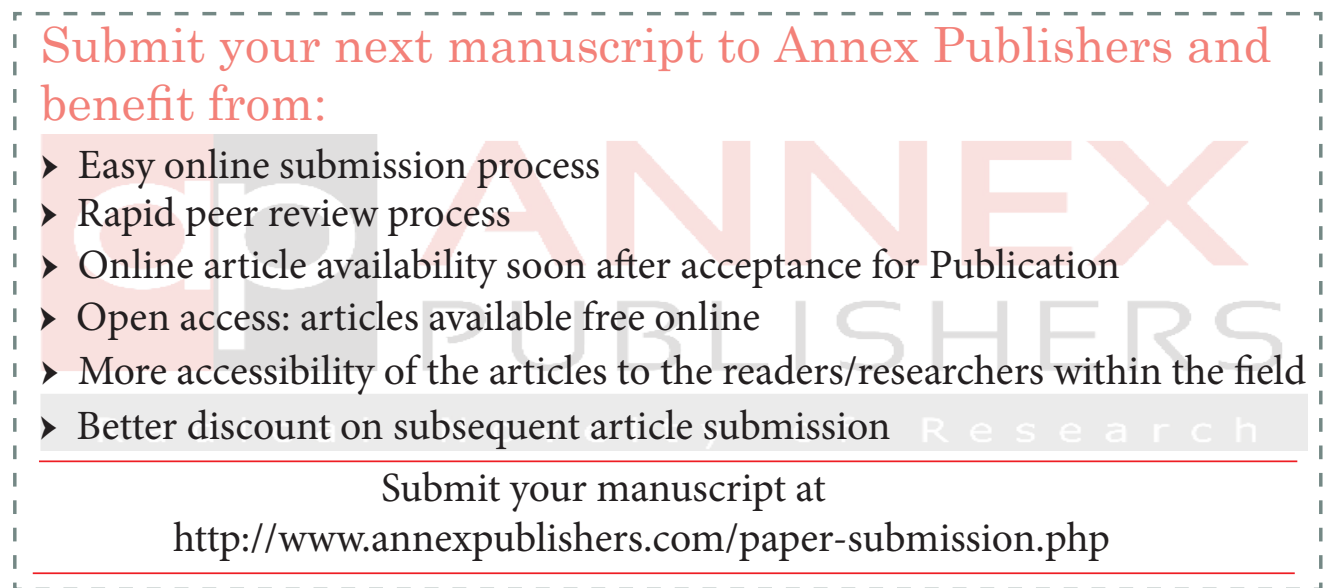

